\title{
Identification of genes induced by BRCA1 in breast cancer cells
}

\author{
Arzu Atalay, ${ }^{\mathrm{a}}$ Tim Crook, ${ }^{\mathrm{b}}$ Mehmet Ozturk, ${ }^{\mathrm{a}}$ and Isik G. Yulug ${ }^{\mathrm{a}, *}$ \\ a Department of Molecular Biology and Genetics, Faculty of Science, Bilkent University, 06533 Ankara, Turkey \\ ${ }^{\mathrm{b}}$ Imperial College Faculty of Medicine, Ludwig Institute for Cancer Research, St. Mary's Hospital, Norfolk Place, London W2 1PG, UK
}

Received 5 November 2002

\begin{abstract}
Inherited mutations of the BRCA1 gene predispose to breast, ovarian, and other cancers. The role of the BRCA1 gene in the maintenance of chromosomal integrity is linked to a number of biological properties of its protein product, including transcriptional regulation. In the present study, we have used suppression subtractive hybridisation ( $\mathrm{SSH}$ ) to identify genes induced by BRCA1 by comparing control MCF7 breast carcinoma cells (driver) with MCF7 cells ectopically expressing BRCA1 (tester) and generated a forward subtracted cDNA library. We screened 500 putative positive clones from this library. Two hundred and ten of these clones were positive by differential screening with forward and reverse subtracted probes and the 65 cDNA clones which showed more than fivefold increase were selected for sequencing analysis. We clustered 46 different genes that share high homology with sequences in the GenBank/EMBL databases. Among these, 30 were genes whose function had been previously identified while the remaining 16 clones were genes with unknown functions. Of particular interest, BRCA1 gene induces the expression of genes encoding DNA repair proteins RAD21 and MSH2, ERBB2/HER2 interacting protein ERBIN, meningioma-associated protein MAC30, and a candidate ovarian tumour-suppressor OVCA1. Northern and Western blot analyses confirmed that the expression of these five genes are up-regulated following BRCA1 overexpression in MCF7 and UBR60-bcl2 cells. This is the first study reporting a set of BRCA1induced genes in breast carcinoma cells by the SSH technique. We suggest that some known genes identified in this study may provide new insights into the tumour-suppressor function of BRCA1.
\end{abstract}

(c) 2002 Elsevier Science (USA). All rights reserved.

Keywords: BRCA1; Breast cancer; SSH; MCF7; Gene expression; Target gene

Germ-line mutations in the BRCA1 tumour-suppressor gene predispose carriers to breast and ovarian cancers and account for approximately $50 \%$ of inherited breast cancers [1]. BRCA1 gene encodes a $220 \mathrm{kDa}$ multifunctional nuclear phosphoprotein involved in different cellular pathways including cellular response to DNA damage, cell cycle, growth suppression, apoptosis induction, ubiquitin ligation, and transcription regulation [2]. Several functional regions have been described in BRCA1: an N-terminal RING finger domain, two nuclear localisation signals, and two BRCA1 carboxyl terminal (BRCT) motifs at the carboxyl terminus. BRCA1 is the main component of the BRCA1-associated genome surveillance complex (BASC) which serves as a sensor for DNA damage. BASC comprises tumour suppressors and DNA damage repair proteins $\mathrm{MSH}$,

\footnotetext{
${ }^{*}$ Corresponding author. Fax: +90-312-266-5097.

E-mail address: yulug@fen.bilkent.edu.tr (I.G. Yulug).
}

MSH6, MLH1, ATM, BLM, the RAD50-MRE11NBS1 protein complex, and DNA replication factor C $[3,4]$. In addition, the carboxyl terminal of BRCA1 acts as a strong transcriptional activator when fused to a heterologous DNA binding domain [5]. BRCA1 co-purifies with RNA polymerase II holoenzyme complex, suggesting that it is a component of core transcription machinery [6]. BRCA1 also interacts with several transcription factors such as p53, CtIP, c-myc, ZBRK1, ATF, E2F, and signal transducer STAT1 [7] and modulates their activity. These findings, together with the interaction of BRCA1 with histone deacetylases (HDACs) and the SWI/SNF-related chromatin remodelling complex, imply that transcriptional regulation is one of the main functions of BRCA1 [8]. In addition, nearly all germ-line BRCA1 mutations involve truncation or loss of the C-terminal BRCT transcriptional activation domain, suggesting that transcriptional regulation is a critical function of the BRCA1 gene. Our 
purpose in this study was to identify the genes whose expression is regulated by BRCA1 and therefore contribute to a better understanding of its cellular functions. We used MCF7 breast carcinoma cell line which has low endogenous BRCA1 expression level and maintains wild-type p53 [9]. We compared the expression profile of control MCF7 cells with MCF7 cells ectopically expressing BRCA1 by performing $\mathrm{SSH}$. We generated a subtracted cDNA library and identified novel BRCA1-induced genes as candidate mediators of tumour suppression by BRCA1.

\section{Materials and methods}

Cell lines and cell culture. MCF7 breast carcinoma cells (American Type Culture Collection) and UBR60-bcl2 cells were maintained in Dulbecco's modified Eagle's medium (DMEM) supplemented with $10 \%$ fetal calf serum, $1 \mathrm{mM}$ glutamine, $10 \mathrm{U} / \mathrm{ml}$ penicillin $\mathrm{G}$, and $10 \mu \mathrm{g} /$ $\mathrm{ml}$ streptomycin, at $37^{\circ} \mathrm{C}$ in $5 \% \mathrm{CO}_{2}$-containing atmosphere. The UBR60-bcl2 cell line (a gift from Dr. Paul Harkin) which expresses BRCA1 under the control of tetracycline-regulated promoter has been previously described [10].

Plasmids and transfections. pCMVmycBRCA1 was constructed by subcloning the full-length BRCA1 insert from pCR3.BRCA1 (provided by Dr. Barbara Weber) into pCMVmyc vector (Clontech laboratories, Palo Alto, CA). pCR3.BRCA1 was cut with HindIII, the ends were filled with Klenow, and SalI linkers were ligated into the ends. The plasmid was digested with SalI/NotI and the BRCA1 cDNA was cloned into pCMVmyc vector (Clontech). MCF7 cells were grown to $80 \%$ confluency $24 \mathrm{~h}$ prior to electroporation. Briefly, cells were harvested with trypsin, washed twice with ice-cold calcium and magnesium-free PBS, and re-suspended in ice-cold PBS. Plasmid DNA was added $\left(30 \mu \mathrm{g} / 15 \times 10^{6}\right.$ cells/cuvette) and electroporation was carried out at $950 \mu \mathrm{F}, 0.22 \mathrm{kV} / \mathrm{cm}(t=19-22 \mathrm{~ms})$ (BioRad Gene Pulser). pEGFP-N2 (Clontech) was used as a control plasmid to calculate the transfection efficiency using the same experimental conditions. Total RNA and protein extractions were performed $24 \mathrm{~h}$ after transfection.

Annexin V staining. Binding of Annexin $\mathrm{V}$ to the cell surface, which is an early indication of apoptosis, was determined with the Annexin V-PE stain (PharMingen, BD Biosciences). Cells were washed twice with cold PBS and then incubated in the dark in $100 \mu$ l binding buffer (0.01 M Hepes, pH 7.4, $0.14 \mathrm{M} \mathrm{NaCl}$, and $0.25 \mathrm{mM} \mathrm{CaCl}_{2}$ ) containing $5 \mu \mathrm{l}$ Annexin V-PE stain per coverslide. The coverslides were washed with binding buffer and fixed in $1 \mathrm{ml}$ of $90 \%$ cold ethanol for $30 \mathrm{~min}$ under dim light. After washing with PBS, Hoechst staining $(300 \mu \mathrm{g} / \mathrm{ml}$ final concentration) was performed for $5 \mathrm{~min}$ in the dark. The coverslides were extensively washed with $\mathrm{H}_{2} \mathrm{O}$ and mounted onto $80 \%$ glycerol droplet. As a positive control for apoptosis, MCF7 cells were treated under $50 \mathrm{~J} / \mathrm{m}^{2}$ ultraviolet light and the same experimental conditions were applied.

Western blot analysis. Cells were harvested using RIPA lysis buffer (10 mM Tris-Cl, pH 8.0, 1 mM EDTA, $150 \mathrm{mM} \mathrm{NaCl,} \%$ NP-40, $1 \%$ $\mathrm{NaDOC}$, and protease inhibitors). Equal amounts of protein extracts were loaded in $10 \%$ (for MSH2 and cytokeratin 18) or $5 \%$ (for BRCA1, Ab-1) SDS-polyacrylamide gels and transferred onto polyvinylidene difluoride (PVDF) membranes. After overnight incubation at $4{ }^{\circ} \mathrm{C}$ in blocking solution (TBS-T: $20 \mathrm{mM}$ Tris- $\mathrm{HCl}, \mathrm{pH} 7.6$, $0.137 \mathrm{M} \mathrm{NaCl}, 0.5 \%$ Tween 20 , and $3 \%$ milk) membranes were incubated for $2 \mathrm{~h}$ at room temperature with mouse anti-human BRCA1 monoclonal (Ab-1, Oncogene Research Products), mouse anti-human MSH2 monoclonal (Ab-1, Oncogene Research Products), or cytokeratin 18 (JAR13 clone, a gift from Dr. D. Bellet, IGR, France) antibodies. Blots were washed three times for $10 \mathrm{~min}$ in TBS-T and incubated with the secondary antibody (Horseradish peroxidase-conjugated anti-mouse IgG, 1:2000, Santa Cruz Biotechnology) for $1 \mathrm{~h}$ at room temperature with constant shaking. After extensive washing, chemiluminescence detection was carried out with the Amersham ECL detection kit according to manufacturer's instructions.

$R N A$ isolation for cDNA subtraction. Total RNA was prepared with TRI Reagent (Sigma). mRNA was isolated from total RNA with poly(A) Spin mRNA Isolation Kit (New England Biolabs) according to manufacturer's specifications. For removal of DNA contamination from RNA samples, the MessageClean Kit (GenHunter) was used according to manufacturer's instructions.

Suppression subtractive hybridisation ( $\mathrm{SSH}$ ). SSH was performed with PCR-Select cDNA Subtraction Kit (Clontech) as described by the manufacturer with minor modifications. In brief, $3.5 \mu \mathrm{g}$ poly $(\mathrm{A})^{+}$ RNA from MCF7 cells electroporated with pCMVmyc used as the driver and $3.5 \mu \mathrm{g}$ from pCMVmycBRCA1-transfected cells was used as the tester to construct a forward subtracted library. Reverse subtraction was also performed where tester cDNA was derived from MCF7 electroporated with pCMVmyc and driver cDNA derived from MCF7 electroporated with pCMVmycBRCA1 using the same experimental conditions. SSH was performed with double-strand tester and driver cDNAs. Primary PCR condition was $94^{\circ} \mathrm{C}$ for $30 \mathrm{~s}, 66^{\circ} \mathrm{C}$ for $30 \mathrm{~s}$, and $72^{\circ} \mathrm{C}$ for $90 \mathrm{~s}$ for 30 cycles in $25 \mu \mathrm{l}$ reaction volume. One microliter of 1/10th diluted primary PCR product was added into a new PCR tube for a second round of PCR. The secondary PCR condition was $94^{\circ} \mathrm{C}$ for $30 \mathrm{~s}, 68^{\circ} \mathrm{C}$ for $30 \mathrm{~s}$, and $72^{\circ} \mathrm{C}$ for $90 \mathrm{~s}$ for 15 cycles. All PCR and hybridisation steps were performed on a Perkin-Elmer 9600 thermal cycler.

Cloning of $c D N A$ mixture. The final PCR-generated forward subtracted cDNA mixture, enriched for BRCA1 up-regulated sequences, was cloned into the cloning vector pGEM-T Easy (Promega) and transformed into supercompetent Escherichia coli strain JM109. The transformed bacteria were plated on $150 \mathrm{~mm}$ ampicillin agar plates containing $100 \mathrm{mM}$ IPTG and $50 \mathrm{mg} / \mathrm{L} \mathrm{X-Gal} \mathrm{and} \mathrm{bacteria} \mathrm{were} \mathrm{grown}$ overnight at $37^{\circ} \mathrm{C}$. Plates were then incubated further at $4{ }^{\circ} \mathrm{C}$ until blue/white staining could be clearly distinguished.

Differential screening of clones. The PCR-Select Differential Screening Kit (Clontech) was used to screen the subtracted cDNA library to analyse the differentially expressed sequences according to manufacturer's recommendations. Five hundred white clones were picked randomly, inoculated into sterile 96-well plates containing LB medium with ampicillin, and grown overnight shaking at $37^{\circ} \mathrm{C}$. Then $1 \mu \mathrm{l}$ of each bacteria culture was used to amplify the cDNA inserts with SP6 and T7 universal primers. The PCR products were then transferred into 96-well plates and denatured in equal amount of $\mathrm{NaOH}$ and $1.5 \mu \mathrm{l}$ of each sample was blotted onto two nylon membranes (Hybond $\mathrm{N}^{+}$) in an identical order. Negative hybridisation controls cDNA1 and cDNA2 (provided by the manufacturer), and BRCA1 cDNA were included as control in the blots. The forward and reverse subtracted cDNA pools in SSH steps were used as probes which were labelled with $\left[\alpha-{ }^{32} \mathrm{P}\right] \mathrm{dCTP}$ using Random Primers DNA Labeling System (Clontech). Two identical blots were hybridised with either forward or reverse probes with the same number of $\mathrm{cpm}$ for each pair and signal intensity was measured by phosphorimaging (Bio-Rad Molecular Imaging System). Two hundred and ten clones which showed more than fivefold increase in signal intensity were again dotted onto membranes and differential screening was repeated two further times.

Sequencing and homology search. All sequencing reactions were performed on double-stranded plasmid templates with T7 and SP6 primers. Sequencing reactions were carried out with the Big Dye terminator cycle sequencing kit and analysed with the ABI 377 DNA sequencer. Partial cDNA sequences were compared with entries in the GenBank/EMBL database using the BLAST homology search program at http://www.ncbi.nlm.nih.gov/blast/.

Northern blot analysis. Total RNA was isolated with TRI Reagent (Sigma). Thirty $\mu$ g of total RNA samples was resolved by formaldehyde gel electrophoresis, run overnight at $50 \mathrm{~V}$, and then transferred to 
nylon membrane (Hybond $\mathrm{N}^{+}$). Purified cDNA inserts were labelled with HexaLabel Plus Kit (MBI Fermentas) and separated by Quick Spin columns (Boehringer-Mannheim). Membrane hybridisation was carried out overnight at $65^{\circ} \mathrm{C}$ in hybridisation buffer $(0.5 \mathrm{M}$ phosphate buffer, pH 7.2, 7\% SDS, $1 \mathrm{mM}$ EDTA, $1 \%$ BSA, and $10 \mu \mathrm{g} / \mathrm{ml}$ salmon sperm DNA, and yeast total RNA) containing at least $10^{7} \mathrm{cpm}$ $\left[\alpha-{ }^{32} \mathrm{P}\right] \mathrm{dCTP}$-labelled cDNA PCR products as probes per membrane. Membranes were sequentially washed in $2 \times$ SSC and $0.5 \%$ SDS, $1 \times$ SSC and $0.5 \%$ SDS, and $0.2 \times \mathrm{SSC}$ and $0.5 \%$ SDS at $68^{\circ} \mathrm{C}$ and the filters were exposed to X-ray film with an intensifying screen at $-70^{\circ} \mathrm{C}$.

\section{Results}

Ectopic expression of BRCA1 in MCF7 breast carcinoma cells

MCF7 cells were transiently transfected with either pCMVmycBRCA1 or a control plasmid pCMVmyc lacking BRCA1 insert. The transfection efficiency, verified by pEGFP-N2 reporter plasmid, was approximately $40 \%$. Under these conditions, less than $1-2 \%$ of cells were apoptotic, as tested by Annexin V staining at $24 \mathrm{~h}$, following transfection with either BRCA1 or control plasmid (data not shown). Thus, at a transfection efficiency of $40 \%$, no more than $5 \%$ of BRCA-1 expressing cells were apoptotic. This indicated that ectopically expressed BRCA1 was not significantly cytotoxic to MCF7 cells under test conditions. BRCA1 or control plasmid-transfected cells were examined for the BRCA1 protein level by Western blot analysis. The results of two representative experiments are shown in Fig. 1. Both control MCF7 cells (lane 1) and the cells transfected with control plasmid without BRCA1 insert (lane 2) demonstrated endogenous BRCA1 protein. As shown in Fig. 1 (experiment 1) ectopically expressed BRCA1 protein level was similar to endogenous BRCA1 level, suggesting that transient transfection resulted in a significant increase in total BRCA1 levels in pCMVmycBRCA1-transfected MCF7 cells (lane 3). Taken together, these results indicated that it was possible to increase BRCA1 levels in MCF7 by transient transfection, without compromising cellular integrity.

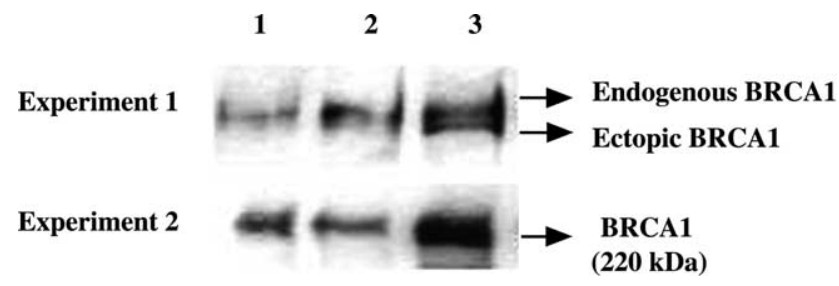

Fig. 1. Ectopic expression of BRCA1 in MCF7 breast carcinoma cells. MCF7 cells electroporated without any plasmid (lane 1), cells transfected with control plasmid pCMVmyc (lane 2), and pCMVmycBRCA1 plasmid (lane 3) are shown. Total protein extracts were prepared and analysed for BRCA1 by Western blot using Ab-1 antibody specific to BRCA1. Blots shown are representative of Western blot analysis from six separate experiments.
Generation of a subtracted library and screening of differentially expressed clones

We used suppression subtractive hybridisation (SSH) technology to identify genes that are differentially expressed in BRCA1-transfected MCF7 cells. SSH was performed with the double-strand tester (MCF7/ pCMVmycBRCA1) and driver (MCF7/pCMVmyc) cDNAs (forward subtraction). Reverse subtraction was also performed where tester cDNA was derived from pCMVmyc-transfected MCF7 cells and driver cDNA derived from pCMVmycBRCA1-transfected cells. Following SSH, differential screening was performed with these forward and reverse subtracted probes in order to identify differentially expressed genes. Five hundred clones were selected at random from the forward subtracted library enriched for BRCA1 up-regulated sequences and the cDNA inserts were amplified. The PCR products were then blotted onto membranes together with control cDNAs and probed with the forward and reverse subtracted cDNA pools. Two hundred and ten of them were screened positive by differential screening with forward and reverse subtracted probes and 65 cDNA clones which showed more than fivefold increase were selected for sequencing analysis (Table 1). Fig. 2 shows an example of duplicate dot blots hybridised with forward (Fig. 2A) and reverse subtracted cDNA probes (Fig. 2B), respectively. Control experiments indicated the subtraction allowed the enrichment of BRCA1 cDNA. As expected, the negative hybridisation controls cDNA1 and cDNA2 were not hybridised.

\section{BRCA1-induced genes in breast cancer cells form several distinct functional classes}

To characterise the 65 differentially expressed clones, the inserts were partially sequenced and the output sequences, compared to the GenBank/EMBL database in order to find homologies with already known genes. Eight clones yielded poor sequence data and eleven genes were represented more than once in the library (Table 1). Overall, 57 clones showed more than $90 \%$

Table 1

Summary of the analysed clones

\begin{tabular}{lc}
\hline & Number \\
\hline Analysed putative positive clones after SSH $_{\text {Confirmed by differential screening }}{ }^{\mathrm{a}}$ & 500 \\
Number of clones sequenced $^{\mathrm{b}}$ & 210 \\
$>90 \%$ homology & 65 \\
$\quad$ Known function & 57 \\
$\quad$ Unknown function & 30 \\
\hline
\end{tabular}

${ }^{\mathrm{a}}$ The cDNA clones which showed more than 5 -fold induction were selected for sequencing.

${ }^{\mathrm{b}}$ Eight clones yielded poor sequence data and eleven genes were represented more than once in the library. 

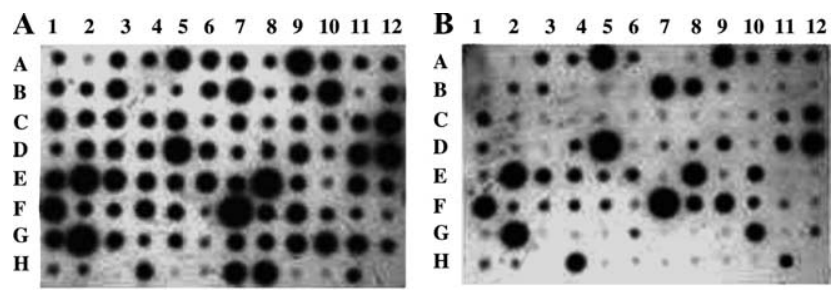

Fig. 2. Differential screening of SSH-selected cDNA clones with forward (A) and reverse (B) subtracted probes. Selected cDNA inserts were PCR-amplified from forward subtracted cDNA library, enriched for BRCA1 up-regulated sequences, spotted in two identical membranes, and hybridised with $\left[\alpha-{ }^{32} \mathrm{P}\right] \mathrm{dCTP}$-labelled forward or reverse subtracted cDNA probes. Rows A-H; test cDNA samples, Rows H3: negative PCR control, H5-H6: cDNA1, H9-H10: cDNA2 as negative control cDNAs, H7-H8: BRCA1, and H12: $\mathrm{NaOH}+$ water). For example E2 cDNA showed no significant increase (1.76-fold), but C3 cDNA (zinc finger protein, LZK1) displayed 7.0-fold increase. The signal intensities were measured by phosphorimager.

homology to known genes. As shown in Table 2, we associated 30 of the genes to a known or putative function: 5 in transcriptional regulation, 3 in intermediate metabolism, 3 in ubiquitin-mediated proteolysis, 2 in chromatin organisation, 3 in DNA repair, 2 in receptor-mediated signalling, and 2 in cytoskeletal organisation. The others were involved in amino acid or ion transport, cell-cell and cell-ECM interaction, endosome or vesicle-trafficking, and $N$-glycan biosynthesis. The Cdc7 protein kinase which is involved in the initiation of DNA synthesis was also induced by BRCA1. The function of the remaining 16 genes was unknown.

\section{Confirmation of BRCA1-induced genes by Northern and Western blot analysis}

Several BRCA1-induced genes reported here are known to be involved in DNA repair (RAD21, MSH2); $[11,4]$ and chromosomal structure maintenance (RAD21, CDC7, SGT1, and HMG1); [12-15]. This observation strongly suggests that at least some of the effects attributed to BRCA1 for chromosomal stability are mediated by these genes. To further analyse their BRCA1-regulated expression, we analysed RAD21 and MSH2 expression in two different cell lines. Both RAD21 and MSH2 were up-regulated following overexpression of BRCA1 in MCF7 cells (Figs. 3A and B) as well as in the UBR60-bcl 2 cell line following BRCA1 induction (Fig. 3C).

Northern blot assays, using both MCF7 and UBR60bcl2 cells, demonstrate that BRCA1 induces ERBIN expression (Fig. 4). OVCA1 that was identified as a candidate tumour-suppressor gene was also studied. The levels of OVCA1 mRNA transcripts (1.1 and $2.3-\mathrm{kb}$ species) were low in MCF7 cells and BRCA1 overexpression caused induction of both transcript forms (Fig. 4A). Finally, MAC30 transcript, whose expression has been reported to be decreased in meningiomas, sch- wannomas, and neurofibromas [16] was also induced in MCF7 as well as UBR60-bcl2 by BRCA1 (Fig. 4B). These studies performed with UBR60-bcl2 cells that stably express BRCA1 at modest levels in an inducible manner [10] confirm and validate our results obtained with a transient expression approach to identify potential BRCA1 target genes.

\section{Discussion}

In the present study, we have used SSH technology to generate a library of partial-length cDNAs representing differentially expressed mRNAs in BRCA1-overexpressing MCF7 cells. SSH combines subtractive hybridisation with PCR to generate a population of PCR fragments enriched for sequences from genes expressed differentially. SSH-mediated cDNA enrichment allows the equalisation of wide differences in abundance of different transcript species. Consequently, differentially expressed transcripts of low abundance can be cloned [17]. Using this approach we were able to identify 46 genes that are up-regulated as a result of BRCA1 overexpression in breast cancer cells.

Several studies have previously reported the identification of BRCA1 target genes in osteosarcoma [10], colorectal cancer [18], mouse BRCA-/- embryonic stem [19], and human embryonal kidney epithelial [20] cells. None of the genes that we report here have been identified in these previous studies. This could be due to the fact that we used a breast cancer cell line to identify potential BRCA1 target genes by the highly sensitive SSH technique.

We report that several DNA damage response (RAD21, MSH2, ASF1A, and CDC7) and chromosomal structure maintenance (RAD21, ASF1A, CDC7, SGT1, and HMG1) genes are positively regulated targets of BRCA1. As BRCA1-deficient cells suffer from both DSB repair deficiency and chromosomal instability [21], at least some of these defects may be attributed to inefficient expression of these target genes in the absence of functional BRCA1.

Several other genes (such as SGT1, UbE3A, and PSMB4) are involved in ubiquitin-mediated protein degradation. This may be expected since BRCA1 itself (together with BARD1) functions as an E3 ubiquitin ligase $[2,22,23]$. The involvement of BRCA1 in ubiquitin-mediated protein degradation could help explain the multiplicity of biological roles ascribed to this protein, including coordination of DNA repair-related events. Other genes involved in distant cellular processes such as intermediate metabolism, cell-cell interaction, receptormediated signalling, endosome-trafficking, or cytoskeletal organisation also appear to be up-regulated by BRCA1 (Table 2). In this context, BRCA1 seems to act like another tumour-suppressor gene, namely p 53 which 
Table 2

List of BRCA1 up-regulated genes in MCF7 breast carcinoma cells

\begin{tabular}{|c|c|c|c|c|c|}
\hline Putative function & Gene name & Accession No. & $\begin{array}{l}\text { Fold } \\
\text { induction }\end{array}$ & Redundancy & $\begin{array}{l}\text { cDNA } \\
\text { insert size }\end{array}$ \\
\hline Amino acid transport & Solute carrier family 38, member 2 (SLC38A2) & XM_028311 & 9 & 1 & $800 \mathrm{bp}$ \\
\hline Cell-cell interaction & $\begin{array}{l}\text { CD24 antigen (small cell lung carcinoma } \\
\text { cluster } 4 \text { antigen) (CD24) }\end{array}$ & XM_087865 & 29 & 1 & $800 \mathrm{bp}$ \\
\hline Cell-ECM interaction & $\begin{array}{l}\text { Integrin, } \beta 1 \text { (fibronectin receptor, } \beta \text { polypeptide) } \\
\text { (ITGB1), transcript variant } 1 \mathrm{E}\end{array}$ & NM_133376 & 6 & 1 & $800 \mathrm{bp}$ \\
\hline Chaperon & $\begin{array}{l}\text { Dystonia 1, torsion (autosomal dominant; } \\
\text { torsin A) (DYT1) }\end{array}$ & NM_000113 & 11 & 1 & $1.1 \mathrm{~kb}$ \\
\hline $\begin{array}{l}\text { Chromatin assembly/DNA } \\
\text { repair and response }\end{array}$ & Anti-silencing function 1A (ASF1A) & AF279306 & 13 & 2 & $500 \mathrm{bp}$ \\
\hline Chromatin structure & $\begin{array}{l}\text { High-mobility group (nonhistone chromosomal) } \\
\text { protein } 1 \text { (HMG1) }\end{array}$ & BC003378 & 9 & 1 & $650 \mathrm{bp}$ \\
\hline Cytoskeleton organisation & Vinculin (VCL), transcript variant meta-VCL & NM_014000 & 7 & 1 & $800 \mathrm{bp}$ \\
\hline Cytoskeleton organisation & Capping protein (actin filament) muscle Z-line, $\beta$ & BC008095 & 14 & 1 & $800 \mathrm{bp}$ \\
\hline DNA repair & $\begin{array}{l}\text { MutS homolog 2, colon cancer, nonpolyposis } \\
\text { type } 1 \text { (E. coli) (MSH2) }\end{array}$ & XM_034901 & 9 & 1 & $600 \mathrm{bp}$ \\
\hline DNA repair & RAD21 homolog (S. pombe) (RAD21) & NM_006265 & 11 & 1 & $500 \mathrm{bp}$ \\
\hline Vesicle-trafficking & $\begin{array}{l}\text { SEC22, vesicle-trafficking protein } \\
\text { (Saccharomyces cerevisiae)-like } 1\end{array}$ & $\mathrm{BC} 001364$ & 11 & 2 & $900 \mathrm{bp}$ \\
\hline Endosome-trafficking & Suppressor of $\mathrm{K}^{+}$transport defect 1 (SKD1) & NM_004869 & 9 & 1 & $700 \mathrm{bp}$ \\
\hline Intermediate metabolism & Fructose-1,6-bisphosphatase 1 (FBP1) & NM_000507 & 9 & 1 & $500 \mathrm{bp}$ \\
\hline Intermediate metabolism & Galactose-4-epimerase, UDP- (GALE) & XM_032314 & 9 & 1 & $400 \mathrm{bp}$ \\
\hline Intermediate metabolism & $\begin{array}{l}\text { NADH dehydrogenase (ubiquinone) } \\
1 \beta \text { subcomplex } 9\end{array}$ & BC007672 & 9 & 1 & $750 \mathrm{bp}$ \\
\hline Ion transport & $\begin{array}{l}\text { ATPase, } \mathrm{Na}^{+} / \mathrm{K}^{+} \text {transporting, } \beta 3 \text { polypeptide } \\
\text { (ATP1B3) }\end{array}$ & NM_001679 & 10 & 1 & $800 \mathrm{bp}$ \\
\hline$N$-Glycan biosynthesis & $\begin{array}{l}\text { Dolichyl-phosphate } N \text {-acetylglucosaminephospho- } \\
\text { transferase } 1 \text { (GlcNAc-1-P transferase) }\end{array}$ & BC008817 & 6 & 1 & $550 \mathrm{bp}$ \\
\hline Nuclear envelope protein & Thymopoietin (TMPO) & U18271 & 11 & 1 & $900 \mathrm{bp}$ \\
\hline $\begin{array}{l}\text { Protein kinase/DNA } \\
\text { synthesis/Meiosis }\end{array}$ & $\mathrm{Cdc} 7$ (CDC7) & AF015592 & 11 & 1 & $800 \mathrm{bp}$ \\
\hline Receptor-mediated signalling & Erbb2 interacting protein (ERBB2IP) (ERBIN) & NM_018695 & 6 & 1 & $700 \mathrm{bp}$ \\
\hline Receptor-mediated signalling & $\begin{array}{l}\text { G protein } \alpha \text { stimulating activity polypeptide } 1 \\
\text { (GNAS) }\end{array}$ & ВC002722 & 13 & 1 & $700 \mathrm{bp}$ \\
\hline Transcription regulation & $\begin{array}{l}\text { C3HC4-type zinc finger protein (LZK1) } \\
\text { (Dif3 homolog) }\end{array}$ & NM_024835 & 7 & 1 & $700 \mathrm{bp}$ \\
\hline Transcription regulation & Activity-dependent neuroprotector (ADNP) & NM_015339 & 9 & 1 & $500 \mathrm{bp}$ \\
\hline Transcription regulation & $\begin{array}{l}\text { Hypoxia-inducible factor } 1, \alpha \text { subunit inhibitor } \\
\text { HIF1AN (FIH-1) }\end{array}$ & XM_030426 & 7 & 1 & $700 \mathrm{bp}$ \\
\hline Transcription regulation & Sex comb on midleg-like 1 (Drosophila) (SCML1) & NM_006746 & 9 & 1 & $600 \mathrm{bp}$ \\
\hline Transcription regulation & Kelch-like protein C3IP1 (C3IP1) & XM_086284 & 7 & 2 & $400 \mathrm{bp}$ \\
\hline Mitochondrial stress response & D-Prohibitin (Bap37) & AF178980 & 8 & 1 & $500 \mathrm{bp}$ \\
\hline Ubiquitin-mediated proteolysis & $\begin{array}{l}\text { Suppressor of G2 allele of SKP1, S. cerevisiae, } \\
\text { homolog of (SGT1) }\end{array}$ & NM_006704 & 8 & 1 & $450 \mathrm{bp}$ \\
\hline Ubiquitin-mediated proteolysis & $\begin{array}{l}\text { Ubiquitin protein ligase E3A, transcript variant } \\
2 \text { (UbE3A) }\end{array}$ & NM_000462 & 9 & 1 & $600 \mathrm{bp}$ \\
\hline Ubiquitin-mediated proteolysis & Proteasome subunit, $\beta$ type, 4 (PSMB4) & XM_047881 & 9 & 1 & $800 \mathrm{bp}$ \\
\hline Unknown & KIAA0725 protein (KIAA0725) & XM_049445 & 12 & 1 & $1.0 \mathrm{~kb}$ \\
\hline Unknown & $\begin{array}{l}\text { Acidic (leucine-rich) nuclear phosphoprotein } \\
32 \text { family, member B (ANP32B) }\end{array}$ & NM_006401 & 9 & 1 & $800 \mathrm{bp}$ \\
\hline Unknown & Candidate tumour-suppressor OVCA1 (OVCA1) & NM_080822 & 12 & 2 & $1.0 \mathrm{~kb}$ \\
\hline Unknown & Hypothetical protein (MAC30), mRNA & XM_031536 & 17 & 2 & $900 \mathrm{bp}$ \\
\hline Unknown & $\begin{array}{l}\text { Similar to tumour metastasis-suppressor; longevity } \\
\text { assurance (LAG1, S. cerevisiae) homolog } 2\end{array}$ & XM_065847 & 12 & 2 & $600 \mathrm{bp}$ \\
\hline Unknown & $\begin{array}{l}\text { DNA sequence from clone RP11-165J3 on } \\
\text { chromosome } 9\end{array}$ & AL583839.1 & 16 & 1 & $800 \mathrm{bp}$ \\
\hline Unknown & Hypothetical protein FLJ23375 (FLJ23375) & NM_024956 & 16 & 2 & $500 \mathrm{bp}$ \\
\hline Unknown & Hypothetical protein MGC2714 (MGC2714) & NM_032299 & 8 & 1 & $500 \mathrm{bp}$ \\
\hline Unknown & Hypothetical protein BC008322 (LOC92106) & NM_138381.1 & 8 & 3 & $700 \mathrm{bp}$ \\
\hline Unknown & Hypothetical protein FLJ20060 & XM_005467.4 & 12 & 2 & $700 \mathrm{bp}$ \\
\hline Unknown & CG2277 gene product (LOC221294) & XM_166297.1 & 7 & 1 & $500 \mathrm{bp}$ \\
\hline Unknown & Hypothetical protein MGC4767 (MGC4767) & XM_045844 & 10 & 1 & $700 \mathrm{bp}$ \\
\hline Unknown & KIAA1007 & XM_168026.1 & 11 & 2 & $700 \mathrm{bp}$ \\
\hline
\end{tabular}


Table 2 (continued)

\begin{tabular}{lllcc}
\hline Putative function & Gene name & Accession No. & $\begin{array}{l}\text { Fold } \\
\text { induction }\end{array}$ & $\begin{array}{c}\text { Redundancy cDNA } \\
\text { insert size }\end{array}$ \\
\hline Unknown & Clone FLB9213 PRO2474 & AF130088 & 11 & 1 \\
Unknown & Chromosome 5 clone CTD-2085H24 & AC025447 & 10 & $700 \mathrm{bp}$ \\
Unknown & CGI-48 protein (LOC51096) & NM_016001 & 13 & 1 \\
\hline
\end{tabular}
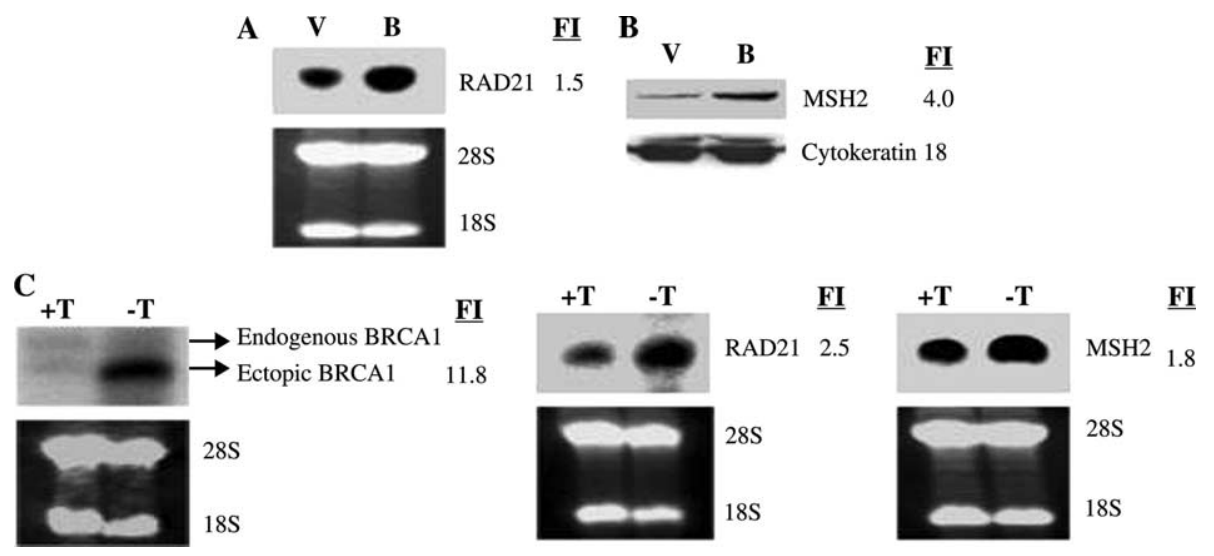

Fig. 3. BRCA1 induces up-regulation of RAD21 and MSH2 in MCF-7 (A, B) and UBR60-bcl2 (C) cells following BRCA1 induction. (A) Northern blot with total RNA from MCF7 cells transfected with control plasmid pCMVmyc (lane V) and pCMVmycBRCA1 plasmid (lane B) confirms BRCA1-mediated induction of RAD21 expression. (B) Western blot analysis of MSH2 protein levels confirms induced expression of MSH2. Cytokeratin 18 was used for equal protein loading control. (C) Northern blot of total RNA from UBR60-bcl2 cells with inducible BRCA1 expression shows over-expression of ectopic BRCA1, RAD21, and MSH2 following tetracycline withdrawal ( $-\mathrm{T})$ at $24 \mathrm{~h}$. Ethidium bromide staining shows equal RNA loading in each lane. "FI" indicates fold induction.

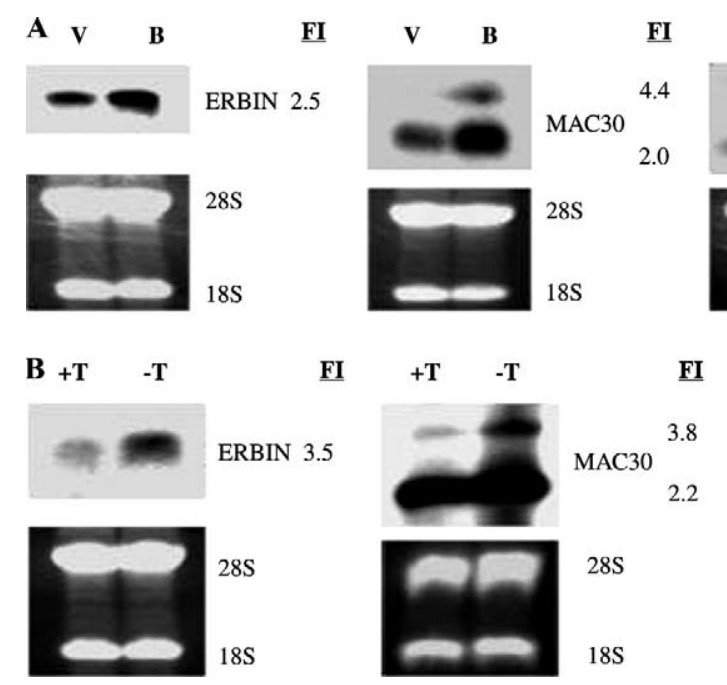

Fig. 4. BRCA1 mediated up-regulation of genes involved in cell signalling or tumour suppression in MCF7 cells and UBR60-bcl2 cells. (A) ERBIN, MAC30, and OVCA1 transcript induction in MCF7 cells (B) ERBIN and MAC30 induction in UBR60-bcl2 cells. Cells were treated and Northern blotting was performed as described in Fig. 3.

also up-regulates a high number of genes involved in many different cellular processes [24]. Although we have not investigated these target genes in tumours yet, we notice that 10 of the 46 genes $(22 \%)$ that we report here (RAD21, ERBB2IP, UbE3A, FBP1, KIAA0725, TMPO, PSMB4, CD24, MSH2, and ATP1B3) are among markers of a 'poor prognosis' gene expression signature identified by DNA microarray analysis of early primary breast tumours [25]. Therefore, we believe that we identified a large set of BRCA1 target genes that may be involved in BRCA1-mediated cellular processes as well as breast carcinogenesis.

In relation to BRCA1-related breast/ovarian carcinogenesis, we further analysed the expression of ERBIN 
and OVCA1. ERBIN, an ERBB2/HER2-binding protein which locates this receptor to the basolateral membrane [26], was also up-regulated by BRCA1. Overexpression of ERBB2/HER2 is frequently observed in breast cancers and its overexpression is associated with poor tumour prognosis [27]. Although it is not known whether ERBIN is able to inhibit ERBB2/HER2 activity, its deregulation results in the mislocalisation of the receptor [26]. This raises the possibility that ERBIN deficit resulting from inactivation of BRCA1 could lead to a loss of epithelial homeostasis, and in consequence, pathological disorganisation in breast carcinoma. Another gene, namely OVCA1 which we show to be up-regulated by BRCA1, was initially identified as a candidate ovarian tumour-suppressor gene located on chromosome $17 \mathrm{p} 13.3$ [28]. This locus displays frequent $\mathrm{LOH}$ in both ovarian and breast cancers [29] and OVCA1 was reported to display reduced expression in breast and ovarian cancers [30]. In addition, ectopic expression of OVCA1 causes a dramatic reduction in cell proliferation in association with accelerated cyclin D1 degradation [30]. Even if additional studies are needed, these observations strongly suggest that BRCA1 mediates its tumour-suppressor functions through a large set of downstream genes involved in DNA repair, receptor-mediated signalling, and ovarian cancer suppression.

In conclusion, we have identified 46 genes whose expression levels are up-regulated as a result of BRCA1 overexpression in breast cancer cells. The properties of several of these genes are consistent with putative tumour-suppressor functions in breast neoplasia. To our knowledge, our study is the first to report BRCA1-induced genes in breast carcinoma cells with the SSH technique. It will now be important to construct a complete profile of BRCA1-regulated genes in order to achieve an integrated view of all the functional events regulated by BRCA1, and to assess how expression of these genes is affected by the BRCA1 status of cells.

\section{Acknowledgments}

We thank Dr. Barbara Weber (University of Pennsylvania Cancer Center, USA) and Dr. D. Paul Harkin (Queen's University of Belfast, Ireland) for providing pCR3.BRCA1 plasmid and UBR60-bcl2 cells. respectively. We thank Dr. Dominique Bellet (Institut Gustave Roussy, France) for Cytokeratin 18 monoclonal antibody. This work was supported by grants from the Scientific and Technical Research Council of Turkey (TUBITAK, TBAG-2062), the British Council Academic Links Scheme Program in Turkey, and Bilkent University (MBG-01-01).

\section{References}

[1] Y. Miki, J. Swensen, D. Shattuck-Eidens, P.A. Futreal, K. Harshman, S. Tavtigian, Q. Liu, C. Cochran, L.M. Bennett, W.
Ding, R. Bell, J. Rosenthal, C. Hussey, T. Tran, M. McClure, C. Frye, T. Hattier, R. Phleps, A. Haugen-Strano, H. Katcher, K. yakumo, Z. Gholami, D. Shaffer, S. Stone, S. Bayer, C. Wray, R. Bogden, P. Dayananth, J. Ward, P. Tonin, S. narod, P.K. Bristow, F.H. Norris, L. Helvering, P. Morrison, P. Rosteck, M. Lai, J.C. Barret, C. Lewis, S. Neuhausen, L. Cannon-Albright, D. Goldgar, R. Wiseman, A. Kamb, M.H. Scolnick, A strong candidate for the breast and ovarian cancer susceptibility gene BRCA1, Science 266 (1994) 66-71.

[2] A.R. Venkitaraman, Cancer susceptibility and the functions of BRCA1 and BRCA2, Cell 108 (2002) 171-182.

[3] R. Scully, J. Chen, R.L. Ochs, K. Keegan, M. Hoekstra, J. Feunteun, D.M. Livingston, Dynamic changes of BRCA1 subnuclear location and phosphorylation state are initiated by DNA damage, Cell 90 (1997) 425-435.

[4] Y. Wang, D. Cortez, P. Yazdi, N. Neff, S.J. Elledge, J. Qin, BASC, a super complex of BRCA1-associated proteins involved in the recognition and repair of aberrant DNA structures, Genes Dev. 14 (2000) 927-939.

[5] A.N. Monteiro, A. August, H. Hanafusa, Evidence for a transcriptional activation function of BRCA1 C-terminal region, Proc. Natl. Acad. Sci. USA 93 (1996) 13595-13599.

[6] R. Scully, S.F. Anderson, D.M. Chao, W. Wei, L. Ye, R.A. Young, D.M. Livingston, J.D. Parvin, BRCA1 is a component of the RNA polymerase II holoenzyme, Proc. Natl. Acad. Sci. USA 94 (1997) 5605-5610.

[7] L. Zheng, H. Pan, S. Li, A. Flesken-Nikitin, L.P. Chen, G.T. Boyer, H.W. Lee, Sequence-specific transcriptional corepressor function for BRCA1 through a novel zinc finger protein, ZBRK1, Mol. Cell 6 (2000) 757-768.

[8] D.A. Bochar, L. Wang, H. Beniya, A. Kinev, Y. Xue, W.S. Lane, W. Wang, F. Kashanchi, R. Shiekhattar, BRCA1 is associated with a human SWI/SNF-related complex: linking chromatin remodeling to breast cancer, Cell 102 (2000) 257-265.

[9] S.K. Kachhap, S.P. Vetale, P. Dange, S.N. Ghosh, Reduced expression of the BRCA1 gene and increased chromosomal instability in MCF-7 cell line, Cell Biol. Int. 25 (2001) 547-551.

[10] D.P. Harkin, J.M. Bean, D. Miklos, Y-H. Song, V.B. Truong, C. Englert, F.C. Christians, L.W. Ellisen, S. Maheswaran, J.D. Oliner, D.A. Haber, Induction of GADD45 and JNK/SAPKdependent apoptosis following inducible expression of BRCA1, Cell 97 (1999) 575-586.

[11] M. Sonoda, T. Matsusaka, C. Morrison, P. Vagnarelli, O. Hoshi, T. Ushiki, K. Nojima, T. Fukagawa, I.C. Waizenegger, J.M. Peters, W.C. Earnshaw, S. Takeda, Scc1/Rad21/Mcd1 is required for sister chromatid cohesion and kinetochore function in vertebrate cells, Dev. Cell 6 (2001) 759-770.

[12] K. Nasmyth, J.M. Peters, F. Uhlmann, Splitting the chromosome: cutting the ties that bind sister chromatids, Science 288 (2000) 1379-1385.

[13] M. Lei, B.K. Tye, Initiating DNA synthesis: from recruiting to activating the MCM complex, J. Cell Sci. 114 (2001) 1447-1454.

[14] K. Kitagawa, D. Skowyra, S.J. Elledge, J.W. Harper, P. Hieter, SGT1 encodes an essential component of the yeast kinetochore assembly pathway and a novel subunit of the SCF ubiquitin ligase complex, Mol. Cell 4 (1999) 21-23.

[15] S. Yamanaka, E. Katayama, K. Yoshioko, S. Nagaki, M. Yoshika, H. Teraoka, Nucleosome linker proteins HMGB1 and histone H1 differentially enhance DNA ligation reactions, Biochem. Biophys. Res. Commun. 292 (2002) 268-273.

[16] M. Murphy, M.J. Pykett, P. Harnish, K.D. Zang, D.L. George, Identification and characterization of genes differentially expressed in meningiomas, Cell Growth Differ. 4 (1993) 715-722.

[17] L. Diatchenko, Y-F.C. Lau, A.P. Campbell, A. Chenchik, F. Moqadam, B. Huang, S. Lukyanov, K. Lukyanov, N. Gurskaya, E. Sverdlov, P.D. Siebert, Suppression subtractive hybridization: a method for generating differentially regulated or tissue-specific 
cDNA probes and libraries, Proc. Natl. Acad. Sci. USA 93 (1996) 6025-6030.

[18] T.K. MacLachlan, K. Somasundaram, M. Sgagias, Y. Shifman, R.J. Muschel, K.H. Cowan, W.S. El-Deiry, BRCA1 effects on the cell cycle and the DNA damage response are linked to altered gene expression, J. Biol. Chem. 275 (2000) 2777-2785.

[19] O. Aprelikova, A.J. Pace, B. Fang, B.H. Koller, E.T. Liu, BRCA1-associated growth arrest is RB-dependent, J. Biol. Chem. 276 (2001) 25647-25650.

[20] P.L. Welcsh, M.K. Lee, R.M. Gonzalez-Hernandez, D.J. Black, M. Mahadevappa, E.M. Swisher, J.A. Warrington, M.C. King, BRCA1 transcriptionally regulates genes involved in breast tumorigenesis, Proc. Natl. Acad. Sci. USA 99 (2002) 7560-7565.

[21] H. Wang, Z-C. Zeng, T.-A. Bui, S.J. DiBiase, W. Qin, F. Xia, S.N. Powell, G. Iliakis, Nonhomologous end-joining of ionizing radiation-induced DNA double-stranded breaks in human tumor cells deficient in BRCA1 or BRCA2, Cancer Res. 61 (2001) 270-277.

[22] R. Hashizume, M. Fukuda, I. Maeda, H. Nishikawa, D. Oyake, Y. Yabuki, H. Ogata, T. Ohta, The RING heterodimer BRCA1BARD1 is a ubiquitin ligase inactivated by a breast cancer-derived mutation, J. Biol. Chem. 276 (2001) 14537-14540.

[23] H. Ruffner, C.A. Joazeiro, D. Hemmati, T. Hunter, I.M. Verma, Cancer-predisposing mutations within the RING domain of BRCA1: loss of ubiquitin protein ligase activity and protection from radiation hypersensitivity, Proc. Natl. Acad. Sci. USA 98 (2001) 5134-5139.

[24] E.E. Balint, K.H. Vousden, Activation and activities of the p53 tumour suppressor protein, Br. J. Cancer 85 (2001) 1813-1823.
[25] L.J. Van’t Veer, D. Hongyue, M.J. Van de Vijver, Y.D. He, A.A.M. Hart, M. Mao, H.L. Peterse, K. Van der Kooy, M.J. Marton, A.T. Witteveen, G.J. Schreiber, R.M. Kerkhoven, P.S. Roberts, C. Linsley, R. Bernards, S.H. Friend, Gene expression profiling predicts clinical outcome of breast cancer, Nature 415 (2002) 530-536.

[26] J.P. Borg, S. Marchetto, A. Le Bivic, V. Ollendorff, F. JaulinBastard, H. Saito, E. Fournier, J. Adelaide, B. Margolis, D. Birnbaum, ERBIN: a basolateral PDZ protein that interacts with the mammalian ERBB2/HER2 receptor, Nat. Cell Biol. 2 (2000) 407-414.

[27] A. Borg, H. Sigurdsson, G.M. Clark, M. Ferno, S. Fuqua, H. Olsson, D. Killander, W.L. McGuire, ERBB2 amplification in breast cancer with a high rate of proliferation, Oncogene 6 (1991) 137-143.

[28] D.C. Schultz, L. Vanderveer, D.B. Berman, T.C. Hamilton, A.J. Wong, A.K. Godwin, Identification of two candidate tumor suppressor genes on chromosome 17p13.3, Cancer Res. 56 (1996) 1997-2002.

[29] A. Hirano, M. Emi, M. Tsuneizumi, Y. Utada, M. Yoshimoto, F. Kasumi, F. Akiyama, G. Sakamoto, S. Haga, T. Kajiwara, Y. Nakamura, Allelic losses of loci at 3p25.1, 8p22, 13q12, 17p13.3, and 22q13 correlate with postoperative recurrence in breast cancer, Clin. Cancer Res. 7 (2001) 876-882.

[30] W. Bruening, A.H. Prowse, D.C. Schultz, M. Holgado-Madruga, A. Wong, A.K. Godwin, Expression of OVCA1, a candidate tumor suppressor, is reduced in tumors and inhibits growth of ovarian cancer cells, Cancer Res. 59 (1999) 4973-4983. 